"iiSabes en qué se parece la mariposa al sapo?»».

Primera incursión a Cuento del hombre que vendía globos, de Grégor Díaz: una poética de la fractura

\title{
Lisandro Gómez
}

Universidad Nacional Mayor de San Marcos

\section{RESUMEN}

El propósito principal de este artículo es esclarecer cuál era la poética dominante en la primera etapa de la dramaturgia de Grégor Díaz. En sus primeras producciones, Díaz apuesta por un claro compromiso con las clases desposeídas y un marcado carácter de denuncia. Esta primera etapa es singular también por un armonioso tratamiento del lenguaje (cercano al lirismo) y por una eficaz experimentación que tiende a quebrar el texto dramático continuamente. Cuento del hombre que vendía globos es uno de los ejemplos más notables de cómo la experimentación textual (y escénica) y el compromiso social consiguen, por medio de un ejercicio de tensión, fusión y rechazo, brindar una imagen del efecto que producen los procesos ideológicos sobre el individuo.

\section{PALABRAS CLAVE}

Grégor Díaz, Gabriel García Márquez, poética de la fractura, parlamentos dislocados, incomunicación, silencio, apertura comunicativa, percepción del espectador.

\section{ABSTRACT}

The main purpose of this article is to clarify what the dominant poetic style was in the first stage of Grégor Díaz's play-writing. In his first productions, Díaz advocates a clear commitment with the dispossessed classes and a strong tone of condemnation. This first stage is also unique due to a harmonious language style (related to lyricism) and an effective experimentation that tends to continually break the dramatic text. Story of a Man Who Sold Balloons is one of the most significant examples of how textual 
experimentation (and stage) and social commitment achieve, by means of exercising tension, fusion and reject, to create an image of the effect that the ideological processes produce about the individual.

\section{KEY WORDS}

Grégor Díaz, Gabriel García Márquez, poetics of rupture, dislocated parliaments, isolation, silence, communicative openness, spectator's perception.

Grégor Díaz nació en Celendín, Cajamarca, en 1933. Shilico, como le gustaba autodefinirse ${ }^{1}$, y artista comprometido como era, dedicó parte de su obra dramática a denunciar la precaria situación de los migrantes en Lima. Su obra adquirió un carácter cada vez más provocador en los momentos previos a la violencia armada, que habría de desatarse en el Perú alrededor de los años 80. Cuento del hombre que vendía globos es, en nuestra opinión, una obra capital dentro del primer periodo creativo de Díaz. Luego, acaso por la vorágine de la guerra, daría un giro radical en su producción al centrarse en la problemática de las parejas de clase media, con evidentes sesgos de psicoanálisis, sin perder por completo su indagación experimental.

Díaz siempre se mantuvo firme en sus postulados estéticos. En una conversación con Roland Forgues, en junio de 1984, ante la pregunta «¿qué es, o debería ser, para ti la creación dramática?» (Forgues 2011: 119), definió con claridad esos principios. Para Díaz, «el teatro es arte y medio de comunicación. Como arte se debe, porque es su naturaleza, a las normas de las bellas artes y bellas letras. Violentar reglas también es normar [...]. Como medio de comunicación, [...] al destinatario» (Forgues 2011: 119) (cursivas nuestras). De forma breve, Díaz brindó dos elementos cruciales de su poética. En su obra, hay un empleo deliberado de los recursos lingüísticos y escénicos, que incluso llega a transgredir dichos códigos; el autor no improvisa, sino elabora, crea, experimenta con pleno conocimiento. En ese sentido, Díaz es un autor que continúa el legado de las vanguardias artísticas, cuya impronta experimental y hermética es patente en su obra. Abocado principalmente a la exploración formal, este dato es capital para entender cuáles son los recursos que pone en escena en la primera parte de su producción dramática. Asimismo, su preocupación por el espectador, por los asistentes a la sala, revela que estamos ante un teatro que busca, sobre todo, como él mismo lo dice, entablar un tipo de

1 Ver «La diáspora shilica», entrevista a Grégor Díaz, en Forgues 2011: 115-127. 
comunicación, sea de emociones o de ideas ${ }^{2}$. Sin duda, esta última parte se coloca del lado de un teatro con mensaje ${ }^{3}$. El mérito de Díaz, en nuestra opinión, radica en haber conciliado exitosamente, en la primera parte de su obra, la experimentación formal con un teatro de denuncia.

A raíz de estas afirmaciones del autor, cabe preguntarse cómo operan estos principios en Cuento del hombre que vendía globos. Aunque fue galardonada con el Primer Premio del Concurso de Obras de Corto Reparto del Teatro Universitario de la Universidad Nacional Mayor de San Marcos en 1975, no sabemos con exactitud cuándo fue compuesta esta pieza. No obstante, esta fecha nos brinda una primera pista. Estamos en los previos, antes de que se desate la violencia. Son momentos álgidos, que aún no hacen sospechar el desborde popular que se avecina ni la violencia armada que se gesta en el interior del país. En este contexto, Cuento del hombre que vendía globos narra los acontecimientos de una madrugada en la vida de dos mendigos, quienes descubrirán que ya no tienen miedo y asumirán, sin reparos, las consecuencias de esta revelación. En esencia, ese es el argumento de la pieza. Lo asombroso es cómo está dispuesta la obra a nivel textual y escénico. Los mendigos tratan de impedir que el policía que vigila esa zona los eche, y para pasar el tiempo están enfrascados en un juego que consiste en fingirse aristócratas cada vez que pronuncian la expresión de alerta: «clave 2». A partir de estas premisas, parece sugerirse que el público va a asistir a una comedia.

Mas no es este el caso. La obra inicia con una profusa mezcla de lenguajes escénicos y una radical fragmentación del texto que interfieren con la representación. ¿Cómo se ubica el público (principal preocupación del dramaturgo) frente a esta pieza desconcertante? ¿Acaso esta vertiginosa puesta en escena de lenguajes no afecta la comunicación que Díaz se ha propuesto como meta de sus piezas dramáticas? A primera vista parece que así fuera. Pero esta primera impresión es falsa. Lo que leemos y vemos en escena forma parte de una poética de la fractura, en la cual la variedad de recursos escénicos y la fragmentación del lenguaje - que incluye los diálogos y parlamentos dislocados y la ruptura de la cuarta pared-son los procedimientos necesarios para generar una verdadera comunicación. Estos recursos, lejos de «interferir» con ella, establecen un canal adecuado entre la obra y los espectadores. La continua fractura del lenguaje es el único medio por el cual se puede establecer un vínculo real

2 Díaz sostiene que «el mejor vehículo para transportar ideas son las emociones» (Forgues 2011: 13).

3 Más adelante, en la misma entrevista, Díaz afirma que «quisiera optar por el camino más difícil: el de la catequización. Que un cura hable a los creyentes no es mérito: hay que salir a convertir» (Forgues 2011: 121). 
con el espectador. No es un adorno, es un imperativo. En ese sentido, la progresión dramática, la transformación de los personajes, está íntimamente unida al cambio de percepción de los asistentes a la pieza. La obra funciona como un mecanismo de higiene ideológica, que diseña un recorrido que va desde la incomunicación hasta la comunicación. Este ensayo, por tanto, busca desentrañar cómo funciona dicha poética dentro de Cuento del hombre que vendía globos.

En la obra se reconocen tres momentos. Cuenta con un prólogo extenso, en el que impera la proliferación y la mezcla de lenguajes, lo cual revela la total fractura entre la representación y los espectadores, que se encuentran desconcertados ante la pieza, al carecer esta, aparentemente, de una historia que contar (Díaz 1991a: 35-40). En este momento, los personajes, Pedro 1 y Pedro 2, se mantienen alejados entre sí, sumidos en su imaginación. Los juegos de luces y el diálogo dislocado que mantienen evidencian una situación de desasosiego y desamparo. La separación entre los personajes constata, al mismo tiempo, la distancia que existe entre la obra y los asistentes. Luego pasamos a una etapa de transición, donde se atenúa la experimentación formal, sin desaparecer por completo, y se atisban los elementos centrales del argumento, que ayudan al espectador a situarse frente a la representación (Díaz 1991a: 40-46). Acá los personajes arrostran su condición y se deshacen del miedo, que los había llevado a evadir su realidad por medio de ciertos «juegos» de identidad, puestos en escena en la primera parte. En este momento es decisiva la fragmentación de los parlamentos, casi siempre unida a la técnica de la ruptura de la cuarta pared, ya que brindan los primeros acercamientos concretos con el público. Los protagonistas interpelan a los asistentes a la sala por esas diminutas rendijas textuales que se abren a cada instante. Por último, la obra cierra con la puesta en escena de «otra» narración, el cuento del hombre que vendía globos (Díaz 1991a: 46-49). Es acá cuando la interpelación es directa. Luego de haber asumido su verdadera condición, los personajes cambian de rutina y ahora la pieza adquiere una nueva forma. La obra concluye con una pregunta difícil que da pie a un diálogo exigido y no por ello menos complicado. El cambio de actitud de los protagonistas obliga al espectador a asumir una posición frente a lo que ha visto. El proceso de transformación se cierra para los personajes, pero solo ha iniciado para los asistentes a la función.

Nos encontramos de madrugada. Dos vagabundos, Pedro 1 y Pedro 2, «miran al público fijamente, están felices y a la expectativa. Se encuentran como los velocistas antes de iniciar una carrera, en la actitud de "a sus marcas"» (Díaz 1991a: 35), sostiene la didascalia. En verdad van a iniciar una carrera cuyo premio es la libertad. El inconveniente radica en que los 
espectadores desconocen por completo el nacimiento que van a presenciar. $Y$ es que su presencia no es la de meros observadores, sino que, de alguna manera, van a participar, van a ser puestos en escena.

Con esas recomendaciones iniciales empieza una serie de secuencias que por su velocidad y ritmo intempestivo desconciertan al lector-espectador. Los personajes, a una señal convenida, van a transformarse en la parodia de dos aristócratas:

1.- (ARISTÓCRATA). ¿Fumamos, señor...?

2.- (ARISTÓCRATA). Si es cigarrillo rubio, sí, caballero.

1.- (ARISTÓCRATA). ¡Rubio, naturalmente...!

2.- (ARISTÓCRATA). Yo no puedo fumar un cigarrillo que no sea, necesariamente, rubio... (Díaz 1991a: 35).

¿Qué está pasando acá? ¿No eran mendigos? ¿Están locos? En el texto que abre la pieza se menciona que ambos personajes realizan dos roles en simultáneo, pueden ser mendigos o aristócratas, intercambiando sus papeles con una rapidez que confunde en un primer momento. Cuando parece que empezamos a comprender, un nuevo cambio interrumpe la percepción del observador: «Desde el segundo plano — afirma el textose escuchan las fanfarrias que anuncian el inicio del show» (Díaz 1991a: 37). A esto se suma un sonido de latidos de corazón tan leve que «el público dude si es un efecto el que están escuchando, [sic] o son los latidos de sus corazones» (Díaz 1991a: 37). Esto es solo el inicio. A la música y al ruido del corazón se le añade la caracterización, por parte de Pedro 2, de un comentarista de fútbol y una persecución en cámara lenta, iluminada únicamente por un cañón seguidor con celofán rojo que, de ser posible, debe tener «efectos estroboscópicos» (Díaz 1991a: 37). Estamos saturados por un flujo de imágenes y efectos sin orden ni concierto aparente.

Esta primera parte, cuyo objetivo es precisamente perturbar al espectador, alcanza su clímax con un diálogo dislocado entre Pedro 1 y Pedro 2, los dos protagonistas. Este es un mecanismo recurrente en la dramaturgia de Díaz que obtiene, en nuestra opinión, su versión más lograda con la magistral El buzón y el aire. Este procedimiento consiste en colocar a dos personajes frente a frente enunciando un monodiálogo distinto. El paralelismo produce un efecto de confusión en el espectador que se ve obligado a cohesionar los dos parlamentos inconexos y establecer algún tipo de sentido. Este es un procedimiento habitual para materializar la incomunicación sobre las tablas. El especial valor de esta escena está enfatizado por medio de un juego de luces que genera la atmósfera propicia para revelar el silencio de un diálogo imposible: 
Un haz de luz roja intermitente, que llega desde el letrero luminoso de la boîte, cae a sus pies, sobre el suelo, mientras en resistencia Pedro 2 recibe, desde atrás, un haz de luz ámbar, concentrado sobre su cabeza. Pedro 1, sobre el rostro, concentrado, tiene un haz de luz azul. Pedro 2 estará de pie: el otro Pedro sentado. Pedro 1 no escucha a Pedro 2, cada uno está en su particular mundo.

2.- (MENDIGO). Ha empezado el espectáculo. En estos momentos al compás de la música, Marión, la Bella Marión, empezará a desnudarse. Los señores dejan de beber.

1.- (ARISTÓCRATA). Mi padre presidiendo la larga mesa de mantel blanco hace sonar la campanilla de plata; $y$, entonces, Almanzor, el Buen Almanzor, el mayordomo principal de la casa que permanece, como todo mayordomo, detrás de la mampara del comedor, hace su aparición, su «majestuosa aparición», como todos los días de Dios, ingresando primero con el pie derecho, en una suerte de cábala, superstición o fe cristiano-pagana (Díaz 1991a: 37-38).

Uno hablará de una cena prodigiosa de la infancia; el otro, de una función de striptease en una boîte. Colocados sucesivamente, da la impresión de un diálogo, cuando en realidad no lo es. La escena se configura a partir de ciertos códigos que remarcan la diferencia y la distancia entre los protagonistas: uno está iluminado de ámbar y de pie, otro, de azul y sentado. La separación física, y visualmente efectiva, se refuerza por un diálogo que no existe, que se resiste al intercambio de palabras. La fragmentación textual nos obliga a aferrarnos a algún elemento. ¿A cuál? Frente a estas ráfagas de sensaciones y de textos el lector-espectador se encuentra inerme. ¿Dónde concentrar nuestra atención?

Esta primera parte de la obra busca la fragmentación textual y escénica de forma deliberada. La fractura de los códigos es el punto de partida para dar inicio a una urgente transformación. En este sentido, la ruptura textual, asentada sobre todo en un diálogo dislocado, cuyos extremos no se unen, significa dos cosas. Por un lado, simboliza el estado en que se encuentran los personajes, cada uno en su particular mundo. La inconsistencia de su identidad, hecha de retazos inconexos, sin unidad posible, aparece en escena. Al estar su interior fracturado por una serie de fantasías (podemos llamarla ideología si queremos), es imposible que accedan a una comunicación real con el otro. Comunicar significa estar dispuesto a entregar algo. Para hacerlo hay que ser. El fracaso de la comunicación de los protagonistas se debe, en primer lugar, a la situación en la que se encuentran inmersos. No obstante, ellos no son los únicos incomunicados, hay también una separación entre el espectador y la representación. El texto se niega a comunicar su narración. En otras palabras, el texto ejecuta la fractura de la comunicación entre el público y la representación. No 
solo habla de la incomunicación entre los personajes, sino que se niega a dialogar con los espectadores. La posición del público es incómoda: presencia un collage de sensaciones y parlamentos que no sabe cómo reunir.

Es curioso cómo la rauda mutabilidad de los personajes en la primera parte de la obra es en realidad la constatación de una situación única. La razón profunda de ese movimiento frenético no es otra que la incapacidad de los protagonistas para cambiar, para mudar de estado. Bajo esta premisa, la segunda parte es, básicamente, un proceso de transformación, que va a derivar en un viraje radical de la posición de los Pedros frente a la realidad que los acomete y que tiene como consecuencia principal la configuración definitiva de sus identidades. Los personajes van a nacer frente a nuestros ojos. Van a nacer y nos van a hablar. Este proceso requiere de la participación de distintos elementos que adquieren valores específicos en la obra: el reconocimiento del policía que los vigila como un hermano; el acercamiento de Pedro 1 a la reflexión como una manera de asumir de forma novedosa su realidad; el esclarecimiento de la famosa «clave 2»y, gracias a esto, su rechazo del miedo son algunos de los momentos capitales de la obra en este sentido. Para los fines de este ensayo, nos interesan dos detalles: el empleo de los parlamentos dislocados (a veces unidos a la ruptura de la cuarta pared) y la conciencia que adquieren los personajes de su miedo.

Es necesario acotar que esta segunda parte ralentiza la experimentación y brinda algunos datos para mejorar la recepción de la obra. El espectador se va enterando de lo que sucede realmente; se revelan las razones del juego escénico y textual. Acá se brinda la información pertinente para definir la situación de los protagonistas. Textualmente, el inicio de esta segunda sección viene marcado por la transformación del escenario y de los personajes, que dan fin a ese extenso diálogo dislocado de la primera parte.

2.- (MENDIGO, se oyen aplausos). El público aplaude. Ha terminado la función.

1.- (ARISTÓCRATA). Ha terminado la cena.

(Todas las luces vuelven a la normalidad. Pausa. Como si no hubiera existido la escena de la boîte) (Díaz 1991a: 43).

A la fiesta del color y de la sensación del inicio se superpone un momento más sosegado en el que descubrimos la causa de tanto alboroto. «iDisimula, Pedro! ¡El policía nos está mirando!», menciona uno de los personajes, Pedro 2, que se preocupa por lo que sucede en su entorno. La indiscreta mirada de este policía ha motivado, como una estrategia de defensa, el juego escénico que hemos presenciado: es preferible pasar 
por loco antes que ser largado de ese lugar. A partir de esta señal vamos adentrándonos en las preocupaciones de los protagonistas. Sin embargo, cabe recordar que la experimentación no ha desaparecido por completo. Hallamos, así, algunos parlamentos dislocados, los cuales fracturan el lenguaje de un modo singular. El personaje habla e, inesperadamente, el lenguaje se quiebra. Cambia de rol de forma intempestiva, sin aviso previo, causando algún malestar en el espectador. No obstante, lo singular de este procedimiento es que, a veces, viene acompañado por la ruptura de la cuarta pared. Es decir, cuando surgen estos desencuentros textuales es porque una invocación del personaje al público acontece:

1.- (MENDIGO, colérico). ¡No me gusta la gente sentimental! ¡No tienes mujer! ¡Y qué! ¿No murió tu hermano y qué? ¿No nos vamos a morir nosotros, también? ¿No murieron tus padres, acaso? (Pausa. Se transforma lentamente en aristócrata). ¿Sabe usted, señor, en qué se parece la mariposa al sapo?

2.- (En aristócrata, con acento de circo, buen circo). ¿La mariposa al sapo, dice usted? ¿La mariposa al sapo? ¡Pues no, señor...! Dígame usted...

1.- (ARISTÓCRATA). En que la mariposa vuela de flor en flor... (En mendigo, gritando al público con mucho dolor). ¡Y al sapo qué mierda le importa...! (Pausa. Y los dos en mendigos). Han apagado la luz... (Díaz 1991a: 43) (las negritas son nuestras).

El juego escénico entre los mendigos y el policía imaginario que los vigila es interceptado por un mensaje que va dirigido directamente, y de forma violenta, hacia el público. Este grito fractura la representación y alude al espectador-lector, lo señala. Es obvio que, de alguna forma, estas bruscas intervenciones gatillan una desconfianza en el público asistente. La obra no se reduce a contar una historia, e incluso cuando parece que lo está haciendo esta opción es polemizada por los protagonistas. Estamos frente a una obra que se rehúsa a ser simplemente entretenida. La historia está, o debe estarlo, en segundo plano; lo principal es diseñar un canal adecuado entre el drama de los protagonistas y los asistentes a la pieza.

$A$ veces, sucede simplemente que las transformaciones adquieren un ritmo distinto debido al drama existencial de los personajes. Las preocupaciones reales de los mendigos desbordan el juego escénico que se han impuesto. Lo que más sorprende es la violencia con la que surgen estas irrupciones en los parlamentos de los protagonistas. La cuarta pared se fractura, se rompe, por una descarga furiosa, por una interpelación de los Pedros hacia el público. Son, finalmente, los espectadores quienes tienen que incorporar y asumir los reclamos de los protagonistas. 
1.- (ARISTÓCRATA). Me la dejé [mi cigarrera] en mi saco de fumar.

2.- (MENDIGO). Eres mendigo.

1.- (MENDIGO). ¡Si vuelvo a serlo, no eres tú quién para indicármelo! ¡Yo no soy mendigo por mi culpa, nunca me llamo a mí mismo «mendigo»! Los demás lo hacen, me ven así porque les conviene. ¡Yo soy un hombre! ¡Qué culpa tengo yo que los demás sean ciegos! Si les digo que esa luz del semáforo es roja, no es que me dé la gana, sino que ese es su color. Yo no tengo la culpa que ellos, para ir adelante, se pongan una venda en los ojos y vean el color verde como rojo. ¡Dios..., quién es el enfermo aquí! ¡Qué culpa tengo yo que se cieguen! (Violentamente, gritando, al público). ¡Daltónicos de mierda! (Pausa breve). (Díaz 1991a: 41) (las negritas son nuestras).

El público es acusado de formar parte de esta conspiración contra los personajes. Así, son asimilados por la obra, que no requiere de ellos solo el rol pasivo de observadores, sino exige una posición distinta, activa, que repercuta de alguna manera en el drama que está frente a ellos.

El uso de este tipo de parlamentos se encuentra dosificado a lo largo de esta segunda sección. Existe una distancia importante entre cada una de las apariciones de este recurso. Lo importante es corroborar que, en cada caso, cumplen una función capital en la toma de conciencia de los personajes. Precisamente, gracias a estas fracturas inesperadas de los parlamentos, Pedro 1 y Pedro 2 van adquirir una nueva interpretación de lo que sucede con ellos y podrán transformar su situación. Sin duda, este viraje es posible al revelar (y mostrarnos) el sentido de la expresión «clave 2», ese código que sintetiza su relación con el policía y que sirve de señal para realizar sus transformaciones. Pedro 1 le explica a su colega el verdadero sentido de esta frase: «"Clave 2"» significa... "cagarse de miedo"... ¡Y por Dios, de verdad, en verdad te digo... A ese policía, ya no le tengo miedo!» (Díaz 1991a: 46).

En este punto se hace patente la falsa mutabilidad de la primera parte. El ritmo delirante de imágenes y sensaciones del inicio es producto del miedo. Lejos de representar un verdadero cambio es simplemente una rutina, una forma de sobrevivir en la ciudad, sometiéndose a la autoridad de los poderes que la gobiernan. El aprendizaje ha sido doble: los protagonistas han aprendido a asumir su miedo, a controlarlo, y los espectadores, que tienen algún tipo de participación en lo que sucede en escena, tienen que hacerse cargo de esos reclamos que van dirigidos hacia ellos. El resultado final de esta segunda sección es el espíritu renovado de los protagonistas, quienes han comprendido que requieren de nuevas estrategias $s i$ desean cambiar su situación. Este cambio todavía no se gesta. Habrá que esperar la última sección para conseguirlo. 
La astucia de Díaz al momento de diseñar la salida argumental al dilema del cambio de acción de sus personajes es inusual. En vista de que su proyecto dramatúrgico implicaba contar una historia y también transmitir un mensaje a los espectadores, Díaz tenía que solucionar no solo cómo sus personajes iban a salir de la situación que los apresaba, sino cuál es el tipo de mensaje final que iba a recibir el espectador-lector de la obra. Ambos problemas son resueltos con el "Cuento del hombre que vendía globos», que da título a la pieza. La importancia de esta solución es tal que Díaz tituló la obra de ese modo.

Este cuento remite a una sección de Cien años de soledad, de Gabriel García Márquez, cuando se narran los mecanismos para enfrentar la peste del insomnio. Uno de ellos es «El cuento del gallo capón». Hasta donde hemos podido investigar, esta es una expresión de uso coloquial en Colombia y hace referencia principalmente a un tipo de discurso que busca prolongar el tiempo sin modificar realmente nada. Es común emplear esta expresión en el ámbito político, cuando se dan excusas o falsas promesas y la intención es mantener las cosas en su estado habitual. Es una manera de atrasar o, incluso, de evadir cualquier tipo de realización. Esta relación con el paso del tiempo también es enfatizada por García Márquez en su texto:

Los que querían dormir, no por cansancio sino por nostalgia de los sueños, recurrieron a toda clase de métodos agotadores. Se reunían a conversar sin tregua, a repetirse durante horas y horas los mismos chistes, a complicar hasta los límites de la exasperación el cuento del gallo capón, que era un juego infinito en que el narrador preguntaba si querían que les contara el cuento del gallo capón, y cuando contestaban que sí, el narrador decía que no había pedido que dijeran que sí, sino que si querían que les contara el cuento del gallo capón, y cuando contestaban que no, el narrador decía que no les había pedido que dijeran que no, sino que si querían que les contara el cuento del gallo capón, y cuando se quedaban callados el narrador decía que no les había pedido que se quedaran callados, sino que si querían que les contara el cuento del gallo capón, y nadie podía irse, porque el narrador decía que no les había pedido que se fueran, sino que si querían que les contara el cuento del gallo capón, y así sucesivamente, un círculo vicioso que se prolongaba por noches enteras (García Márquez 2002: 44-45).

Este «juego infinito» permite que el tiempo transcurra sin que realmente se llegue a contar la historia que se ha prometido. De hecho existen algunas similitudes palpables entre el cuento de García Márquez y el de Díaz, que no se detienen en el parecido formal. La estructura misma de los cuentos es bastante similar, salvo que en la versión de Díaz hay un 
componente aditivo que permite que la expresión «¿Quieres que te cuente el cuento del hombre que vendía globos?» crezca con cada repetición. Por más que el parecido es evidente, el empleo que hace el dramaturgo peruano de este recurso es, en nuestra opinión, radicalmente distinto. $\mathrm{Si}$ en Márquez es un pasatiempo, en Díaz se trata de una estrategia que tiene como finalidad cuestionar al lector-espectador de la obra.

Esta nueva estrategia aparece, y esto es lo importante, por iniciativa de los propios protagonistas. Pedro 1 afirma: «ya me cansé de jugar a lo mismo... Siempre somos iguales o dos mendigos, o dos aristócratas...! ¡No cambiamos! Me aburre escucharte todas las noches cómo se desnuda la Bella Marión (Díaz 1991a: 47). Esto da pie a una nueva propuesta, otro juego, van a interpretar roles distintos: Pedro 1 hará de mendigo y Pedro 2, de aristócrata. Pero el primer Pedro le advierte a su colega: «te vas a arrepentir [...] ahora vamos a jugar a fondo, para siempre; [sic] definitivamente» (Díaz 1991a: 47). Estas palabras son el anticipo de un mecanismo que busca representar el diálogo imposible entre las clases desposeídas y aquellas que controlan la ciudad. En este nuevo juego se establece una comunicación virtual, imaginaria, entre ambos sectores. Se trata de un diálogo, sin duda difícil, pero concertado. Aunque existen resistencias, mientras avanza la conversación el reclamo se hace imperativo, al punto que da pie a un tipo de acción visualmente agresiva. Esto es patente si comparamos el inicio de esta escena con su término, que coincide con el final de la obra:

1.- (MENDIGO). ¿Quieres que te cuente el cuento del hombre que vendía globos?

2.- (ARISTÓCRATA). ¡Qué manera de hablar es esa! ¿Quién le autorizó a tutearme a usted?

1.- (MENDIGO, indignado). Yo no te dije que me dijeras: «iQué manera de hablarme es esa! ¿Quién lo autorizó a tutearme a usted?», sino, simplemente, si quieres que te cuente el cuento del hombre que vendía globos a mitad de la esquina.

[...]

1.- (MENDIGO, más indignado). ¡Yo no te he dicho que repitas lo que yo digo! Sino, si quieres que te cuente el cuento del hombre que vendía globos [...] (Ahora escuchamos nítidamente a Pedro 2 pidiendo perdón). [...] (Con un palo imaginario empieza a pegarle a Pedro 2). [...]

(Suena el pito de la fábrica, los dos se incorporan violentamente. Miran desafiantes al público a quienes gritan a coro):

1 y 2.- (MENDIGOS). ¿Quieren ustedes que les contemos el cuento del hombre que vendía globos a mitad de la esquina? (Congelan el gesto) (Díaz 1991a: 47). 
La pregunta con la que cierra la obra muestra que Díaz ha procedido con cuidado al diseñarla y que, en realidad, el propósito comunicativopedagógico no se ha perdido de vista en ningún momento. Esa pregunta examina frontalmente la posición misma del espectador. La obra ha puesto en escena la incomunicación para disolverla por medio de un proceso que va desde el silencio y la distancia hasta una nueva apertura comunicativa. El paso de cercados a cercadores se ha gestado ante nuestros ojos. Pero este proceso de aprendizaje no compete únicamente a los protagonistas, sino al espectador-lector. Por medio de la fragmentación del lenguaje, en diálogos y parlamentos, y la ruptura de la cuarta pared, Díaz ha conseguido de forma deliberada transformar la percepción del público: lo ha colocado ante las causas de la acción dramática y exige de él una posición concreta. De esta forma, se disponen los elementos imprescindibles de toda comunicación. La respuesta del público es al mismo tiempo la oportunidad de abrir definitivamente este diálogo o, como ha sucedido casi siempre, volver a cerrarlo. La respuesta a esa incomoda pregunta ha quedado palpitando en los labios y en la mente de cada uno de los asistentes al teatro.

La primera parte de la obra dramática de Grégor Díaz se elabora, en buena medida, a partir de una poética de la fractura. Esta poética implica un doble esfuerzo comunicativo tanto en el emisor, que no puede transigir en su experimentación creativa, como en el receptor, que se ve obligado a encarar un teatro que se rehúsa simplemente a representar historias. El teatro de Díaz interpela al espectador de forma provocadora e incisiva. Por medio de la fractura del lenguaje y de los códigos escénicos, Díaz muestra la situación de desamparo de sus personajes y, sobre todo, diseña un recorrido que no termina en la escena, sino que se dirige hacia la conciencia del espectador. Por medio de estas «interrupciones» del flujo textual se alcanzan los elementos necesarios para una verdadera comunicación entre la pieza y el espectador. Asimismo, la transformación de los personajes en escena tiene como recíproco el cambio obtenido en la percepción del público. La saturación del lenguaje y de los elementos en escena tiene como propósito principal purificar el canal comunicativo. Lejos de obstruir, es una vía - acaso la principal - para establecer un nexo real entre lo que sucede sobre el escenario y dentro de la mente y el corazón de cada uno de los observadores. 


\section{REFERENCIAS BIBLIOGRÁFICAS}

ALTHUSSER, Louis (1981). Ideología y aparatos ideológicos de Estado. Lima: Fondo Editorial de la Universidad Nacional Mayor de San Marcos.

BARTHES, Roland (2006). Crítica y verdad. México D. F.: Siglo XXI Editores.

BUSHBY, Alfredo (2011). Románticos y posmodernos. La dramaturgia peruana de cambio de siglo. Lima: Fondo Editorial de la Pontificia Universidad Católica del Perú.

DÍAZ, Grégor (1991a). Cuento del hombre que vendía globos. Teatro peruano: quince obras. Lima: Lluvia Editores y Lipemanía Teatro.

(1991b). El buzón y el aire. Teatro peruano: quince obras.

Lima: Lluvia Editores y Lipemanía Teatro.

EAGLETON, Terry (2005). Ideología: Una introducción. Barcelona: Ediciones Paidós.

FORGUES, Roland (2011). Hablan los dramaturgos, tomo 4. Lima: Editorial San Marcos y Fondo Editorial de la Universidad Ricardo Palma.

GARCÍA MÁRQUEZ, Gabriel (2002). Cien años de soledad. Lima: Ediciones Peisa y Empresa Editora El Comercio. 